\title{
PNAIC: ACONTRIBUIÇÃODAS PRÁTICAS METODOLÓGICASDO PNAIC NAS AVALIAÇÕES INTERNAS DE LÍNGUA PORTUGUESADOS ALUNOS DO 3ㅇ ANO DA EMEF VER. ABELARDO LEÃO, NO MUNICÍPIO DE LIMOEIRO DO AJURU/PA
}

\author{
1.Elcilene da Silva Coelho Martins emailscmelcilene@yahoo.com \\ 2.Francicleide Miranda Ferreira emailmirandafrancicleide826@gmail.com \\ 3.Joana D'arc Rocha de Vasconcelosemailjoanadvv@gmail.com
}

RESUMO

Este artigo trás como título PNAIC: Acontribuição daspráticas metodológicas nos resultados das avaliações internas de Língua portuguesa dos alunos do $3^{\circ}$ ano da EMEF Ver. Abelardo Leão, no Município de Limoeiro do Ajuru-Pa, o referido estudo parte da seguinte questão norteadora: qual a contribuição da pratica metodológica do PNAIC para modificar o resultado das avaliações de língua portuguesa dos alunos do 3o ano da EMEF Ver. Abelardo Leão no município de Limoeiro do Ajuru/PA? A pesquisa tem como objetivo central analisar a contribuição das práticas metodológicas do PNAIC nos resultados das avaliações internas de língua portuguesa dos alunos do $3^{\circ}$ ano da EMEF Ver. Abelardo Leão no Município de Limoeiro do Ajuru/PA. Pretendemos apresentar situações vivenciadas/percebidas na escola, no sentido de contribuir e provocar "novas" reflexões a cerca das políticas pública de formação continuada e repensar sobre a avaliação. Para esta empreitada, utilizamos a pesquisa qualitativa, análise documental e entrevista semi-estruturava, além da pesquisa mista. Nesse sentido, constatamosque a política pública desenvolvida através da pratica pedagógica do PNAIC é muito boa, deixou seu legado, porém não conseguiu deixar um resultado exitoso para asavaliações. Diante disso, constatamos que não houve o comprometimento entre o que foi pactuado, assim, o pacto foi quebrado. Em síntese, só criar política pública não basta, é preciso fazer acontecer no chão da sala de aula e manter o compromisso social, político, econômico e educacional. Dessa forma, é possívelvislumbrar melhorias nos resultados do aprendizado dos alunos.

Palavras-chaves: PNAIC, metodologias, avaliação.

1. INTRODUÇÃO 
O presente estudo emerge inicialmente em saber sobre "A contribuição da prática metodológicado PNAIC nos resultados das avaliações de Língua portuguesa dos alunos do $3^{\circ}$ ano da EMEF Ver. Abelardo Leão, no Município de Limoeiro do Ajuru$\mathrm{Pa}$. Diante das observações nas avaliações internas de língua portuguesa dos alunos, a investigação desdobrou-se na seguinte questão norteadora: qual a contribuição da prática metodológica do PNAIC nos resultados das avaliações internas de Língua Portuguesa, dos alunos da EMEF VER. Abelardo Leão, no município de Limoeiro do Ajuru/Pa?

Ainda nesse sentido apresentamos como objetivo central analisar se as metodologias do PNAICconseguiram modificar os resultados das avaliações internas de língua portuguesa desses alunos.Nesse contexto constatamos que a pesar de estarmos vivendo na era do conhecimento, no entanto,não se observa avanços no que tange a educação, mesmo rodeado de informações, de programas, políticas de formação continuado, nãopercebemos que esses aparatos têm agregado grandes vantagens ao ensino.

O desejo de realizar esta investigação surgiu de uma conversa entre pares de professores ao observar o índice alarmante de alunos retidos no $3^{\circ}$, porque não conseguiram bons resultados nas avaliações internas de língua portuguesa. Sendo assim, nos propomos investigar a eficácia do PNAIC no que tange esses resultados, já que se trata de um programa de grande dimensão por ser construído da parceria entre Entes Federados e universidades.

Para melhor entendermos o problema, partimos de três objetivos principais: analisar como ocorreu a logística do programa PNAIC e a prática metodológica dentro do contexto da sala de aula; comparar as avaliações internas de língua portuguesa dois anos antes e dois anos após a adesão do programa; analisar o que era levado em consideração dentro do processo avaliativo de língua portuguesa.

Para essa empreitada surgiu ás seguintes indagações: como ocorreu a logística do programa PNAIC e a prática metodológica se materializava dentro do contexto da sala de aula? Qual o resultado das avaliações internas de língua 
portuguesa a partir da adesão do programa PNAIC? O que era levado em consideração dentro do processo avaliativo de língua portuguesa?

Para atender os objetivos deste empreendimento, realizamos uma pesquisa de natureza qualitativa, primeiro foi desenvolvida uma pesquisa de caráter exploratório, com o intuito de buscar informações sobre o fenômeno pesquisado, concomitante a isso, durante a investigação foi realizada pesquisa bibliográfica com suporte em autores.

Para a obtenção dos resultados utilizou-se como recurso investigativo com enfoquequalitativo, desenho exploratório, entrevista semiestruturada, pesquisa bibliográfica, fundamentada nos seguintes autores: Nóvoa (1995 a 1997), Luckesi (2011 a 2003) Hoffmam (2005)

Para a busca de informações sobre o fenômeno pesquisadorecorremos ao campo empírico. Como lócus de pesquisa a coleta ocorreu na Escola Municipal Vereador Abelardo Leão, localizada a Rua Juscelino Kubstchek, s/n, bairro da matinha, entre as travessas Onezinho Rodrigues e Umarizal. Obtivemos como informantes quatro sujeitos que foram denominados por nomes fictícios, de: João Maria, José e Pedro.

A principal motivação em realizar esta pesquisa, surgiu após observarmos que os alunos da EMEF Ver Abelardo Leão não obtinham bons resultas nas avaliações internas de língua portuguesa. Diante disso, fazer essa investigação vai ajudar no sentido de adquirir conhecimento pessoal e contribuir com a sociedade na busca por melhorias na qualidade do ensino, e serve também como material de estudo para futuras pesquisas e novas reflexões no que tange a avaliação e o que se deve levar em consideração dentro do processo avaliativo.

2 - METODOLOGIAS E PRÁTICAS PEDAGÓGICAS E SUA CONTRIBUIÇÃO NO APRENDIZADO DO ALUNO

Vivemos na era do conhecimento, dos avanços e das descobertas, cercada de políticas de formação continuada, de inovações de praticas pedagógicas e metodológicas, mas apesar disso, ainda existem muita fragilidade no que tange a 0 processo avaliativo, parece que a avaliação continua sem perspectivas de grandes 
inovações, pois ainda estão sendo usadas como instrumento de controle, classificatórias e excludentes.

O Pacto Nacional pela Alfabetização na Idade Certa PNAIC através de um compromisso formal assumido pelo Governo Federal, do Distrito Federal, dos Estados, Municípios universidades, dispostos a mobilizar todos os seus esforços e recursos na valorização dos professores e escolas, no apoio pedagógico, com materiais didáticos de alta qualidade para todas as crianças, dos sistemas adequados de avaliação, gestão e monitoramento, para assegurar a plena alfabetização de todas as crianças até os oito anos de idade, ao final do $3^{\circ}$ ano do ensino fundamental (2012a).

Diante disso, a logística do programa PNAIC era mobilizar esforços em criar metodologias que resolvessem o problema da alfabetização matemática e em língua portuguesa,garantindo alfabetizar ás crianças de $1^{\circ}$ ao $3^{\circ}$ ano até 8 anos de idade, além disso, valorizar o professor,oferecer formação continuada para os mesmos, no local do professor a fim de melhorar a interação entre pares, disponibilizar materiais didáticos pedagógicos, com base nos seguintes princípios:

- Prática reflexiva: este princípio está relacionado ao fazer cotidiano do professor em seu contexto de atuação, que deve servir para uma tomada de atitude antes do contato com os infantes, sempre com a preocupação de buscar conhecimentos científicos para relacionar com os conhecimentos práticos.

- A mobilização dos saberes docente: esta constitui como ponto crucial no ato da formação presencial, ao reconhecer que todo professor possui saberes dentro do seu fazer pedagógico.

- A constituição da identidade profissional: Esta pode ser considerada a marca do profissional porque é uma tomada de postura do professor em investir do seu próprio conhecimento, reconhecer-se como um sujeito com capacidade de transformar seu ambiente de trabalho, buscar estratégias dentro de seus conhecimentos práticos com o intuito de modificar aquele contexto, e uma reflexão de sua trajetória enquanto profissional [...] (BRASIL, 2012c, p. 13).

Diante do que propõe a logística do programa PNAIC, o principal eixo era oferecer formação continuada ao professor no seu contexto de atuação para compartilhar seus saberes pedagógicos, e ter a liberdade para associar o sabercotidiano com o saber científico. Além disso, construirsua identidade como 
agente do processo de ensino, investindo no seu conhecimento e buscando estratégias para melhorar sua atuação profissional, em busca da melhoria na aprendizagem do educando.

Em consonância com essa idéia, Nóvoa (1997) defende que a formação continuada deve acontecer no espaço do professor;

\begin{abstract}
A formação continuada é antes de tudo, uma releitura das experiências que ocorreram na escola, significando uma atenção prioritária às práticas dos professores, ressaltando que no espaço de formação continuada é o professor em todas as suas dimensões coletivas, profissionais e organizacionais que concebe essa formação, como uma intervenção educativa solidária aos desafios de mudanças das escolas e dos professores. (NÓVOA, 1997 p. 45)
\end{abstract}

Sendo assim, a logística do programa em valorizar o professor como principal ator do processo educativo, tem como premissa, oferecer formação continuada para professor no seu contexto de trabalho, valorizar suas experiências, bagagem cultural, facilitar a interação e troca de experiências entre pares de professores, atende o que é proposto por de Nóvoa (1997).

Contraponto a essa idéia, o entrevistado JOÃO (2019), faz o seguinte relato;

É complicado trabalhar as metodologias do programa, porque tem muitas exigências que não dava para gente cumprir. No começo eles prometeram em ajudar financeiramente a gente, durante 4 meses nos recebemos a ajuda financeira de duzentos reais, alguns materiais didáticos pedagógicos, e tinha formação continuada, só que a gente tinha que vir das nossas localidades para participar das formações na sede do município, isso ficava difícil nunca houve formação na nossa escola.Depois dos 4 meses, deixaram de pagar os duzentos reais, os materiais pedagógicos não tinha mais, dessa forma não tinha condições de vir para as formações ( JOÄO, 2019).

Diante dessa assertiva, percebemos que houve um contraponto entre o que propõe o programa PNAIC e as considerações teóricas feitas por Nóvoa (1997), das falas dos entrevistados. Percebemos a desvalorização dos professores, a negligência na formação continuada, que não ocorreram no contexto do professor conforme é garantido no documento do programa e nas teorias que serviram de suporte para a pesquisa.

Ainda nessa mesma perspectiva, Furtado (2015) discorre sobre a formação continuada para professor: 
[...] Está inserida em um movimento histórico articulado aos meandros das relações sociais, políticas e econômicas que a determina. Lançar-se por esse caminho significa assumir o desafio de buscar compreender tais determinações como fundamento para apreender o movimento real pelo qual se constituem e traduzem suas finalidades últimas enquanto proposta de formação. (FURTADO, 2015, P. 21).

Para Furtado (2015), a formação continuada não é um fato isolado nem se encontra alheio aos problemas sociais, ao contrário, faz parte de um movimento que é concebida em torno de uma questão social, política, econômica e cultural constituída aos meandros das relações sociais. Portanto, a formação continuada é um movimentoreal e tem finalidades.

Seguindo essa linha de raciocínio e diante das ponderações feitas por Nóvoa (1997) em uma entrevista cedida á editora porto, ao falar sobre a profissão de professor, quando foi perguntado de que forma o governo e a própria escola pode agir para melhorar a formação do professor, respondeu o seguinte:

Eles devem criar condições básicas com infra-estrutura e incentivos á carreira profissional, no entanto, só o professor pode ser responsável por sua formação. [...] Historicamente, os docentes desenvolveram identidades isoladas, refiro-me á participação nos planos de regulação do trabalho escolar, de pesquisa, de avaliação conjunta, e de formação continuada para permitir partilha de tarefas, estimular o debate ea reflexão, participar de movimentos pedagógicos que reúne profissionais de áreas diversas. [...], não quero tirar a responsabilidade do governo, mas sua intervenção deve se resumir a garantir meios e condições de trabalho NÓVOA, Pg. 192.

Em linhas gerais, a discussão de Nóvoa converge comas colocações de SARTORI (2013, p. 233) no que diz: "O que se pode esperar minimamente de uma prática metodológica, é que o processo formativo inquiete os protagonistas do processo de ensino-aprendizagem, tornandoos professores mais comprometidos com o fazer do seu ofício". Em suas palavras, o autor convoca todos os protagonistas do ensino aprendizagem, a engajarem-se, na luta por um melhor ensino, pede compromisso ao ensinar. 


\section{1- AVALIAÇÃO DA APRENDIZAGEM COMO PROCESSO PEDAGÓGICO, NÃO COMO INSTRUMENTO AVALIATIVO.}

Entendemos que a avaliação da aprendizagemé umprocesso pedagógico etambém um direito particular do professor com seus alunos, que deve ter como prerrogativa, avaliar para entender o modelo de sociedade, o tipo de formação humana e como ela se desenvolve, não somente para decodificar conhecimento, mas buscar entender como esse conhecimento está sendo decodificado.

De outra forma, se fizermos da avaliação uma prática acirrada, avaliar pelo processo da meritocracia, ou seja, por meio do mérito dos alunos através de nota, corremos o risco de impedir o aprendizado do aluno e levarmos a um resultado danoso, pois o processo avaliativo pode intervir psicologicamente gerando medo e timidez; no campo filosófico, pode tornar um ser humano melhor; no social, pode causar a evasão escolar e no campo pedagógico, ela facilita a socialização e interação entre aluno e o professor.

Conforme Vasconcellos (2005, p.37)

A prática da avaliação escolar chega a um grau assustador de pressão sobre os alunos, levando a distúrbios físicos e emocionais: mal-estar, dor de cabeça, "branco", medo, angustia, insônia, ansiedade, decepção, introjeção de autoimagem negativa. Uma escola que precisa recorrer à pressão da nota logo nas series iniciais, é certamente, uma triste escola e não está educando, é uma escola fracassada.

De maneira que a avaliação dependendo da forma como é elabora e o grau de exigência feita, pode trazer resultado desastroso ao ser avaliado, é preciso que o ato de avaliar seja pensado no aluno, como um ser unilateral, deve ser abordada de uma forma onde não cause medos, angústias, ansiedade entre outros fatores psicoafetivos .Para muitos professores, o fracasso ou sucesso dos alunos se restringem ao resultado nas avaliações, e ainda existem aqueles que utilizam a avaliação como punição, intimidação gerando um desconforto, conforme preconiza o autor abaixo:

Uma forma de castigar um pouco mais sutil [...], que existiu no passado e ainda existe, é a prática pela qual o professor cria um clima de medo, tensão e ansiedade entre os alunos: faz uma pergunta a um deles, passando-a para um segundo, terceiro, quarto, e assim por diante, gerando tensão nos alunos que podem vir a ser os subseqüentes na chamada. Deste modo, a classe toda fica tensa, já que cada um espera ser o próximo. (LUCKESI, 2011, p. 49) 
Dessa forma, o aluno não se sente sujeito do próprio conhecimento, mas se vê obrigado a dar uma resposta sem muitas vezes saber do que se trata, ele normatiza como se todos estivessem em pé de igualdade, desconsidera as características próprias de cada um, quando faz a pergunta a um depois passa para os outros, causando tensão, de forma meritocrática, fazendo divisão entre o que sabe a resposta e o que não sabe, ou tem medo de responder num contínuo processo de exclusão.

Nosso sistema educacional não se preocupa com os caminhos de avaliação na perspectiva da aprendizagem e sim com a aprovação e reprovação dos alunos, diante disso, "o nosso exercício pedagógico escolar é atravessado mais por uma pedagogia do exame que por uma pedagogia do ensino/ aprendizagem." (LUCKESI, 2003, p. 18) em outras palavras esse modelo de avaliação não se preocupa com a construção de saberes, mas apresenta uma tendência em voltar-se para aprática autoritária e repressora da avaliação.

Isso se evidenciou ao indagarmos a Maria (2019) nossa entrevistada, o que ela avalia e como ela avalia seus alunos, a resposta foi:

Eu avalio através da prova escrita, a freqüência, os trabalhos extra-classe, os trabalhos que ele faz na classe, a participação na sala de aula, o comportamento tudo isso. Na resposta da professora observamos que ela não leva em consideração os aspectos cognitivos, não se preocupa com o que ensinar e o que deveria ensinar, o que o aluno sabe e o que deveria saber.

Em linhas gerais, Vasconcelos, (1995) discorre sobre avaliação como instrumento de opressão que gera desconforto ao aluno, Luckesi (2011) aborda a avaliação como forma de castigo, em outra citação Luckesi( 2003) como exame não como ensino. Para Hoffmann (1993) a avaliação de cunho classificatório torna-se "[...] um instrumento autoritário e frenador do desenvolvimento de todos os que passarem pelo ritual escolar [...]". Levando em consideração as discussões feitas por esses teóricos, no que tange ao processo avaliativo, percebemos que as falas da entrevistada apontam para uma tendência avaliativa aos moldes tradicional. 
Já os demais sujeitos de nossa pesquisa,quando indagados a respeito da contribuição do PNAIC nos resultados das avaliações internas de língua portuguesa,a resposta foi: "Eu acredito que se houve resultado positivo, como se observou em alguns alunos, não deve ser atribuído ao PNAIC, e sim graças aos esforços dos professores que deram sua a contribuição trazendo as famílias" PEDRO (2019)

Ao observarmos as falas dos entrevistados e os resultados das avaliações dos anos de 2011 a 2015, notamos que as práticas avaliativas estiveram ancoradas numa concepção como "julgamento de valor dos resultados alcançados" Hoffman, 2005, p. 14. Em suas análises isso significa reduzir o ato de avaliar a uma perspectiva sentenciadora, que pouco contribui para pensar o processo educativo.

Conforme mostra o quadro dos resultados das avaliações, da Escola Vereador Abelardo Leão, através dos dados Estatísticos de Língua Portuguesa dos anos de 2011 a 2015.

Resultado das avaliações de língua portuguesa dos alunos do $3^{\circ}$ ano das séries iniciais/Limoeiro do Ajuru-Pa, anos 2011 a 2015.

\begin{tabular}{|l|l|l|l|l|}
\hline ANOS & $\begin{array}{l}\text { № } \\
\text { ALUNOS }\end{array}$ & APROVADOS & REPROVADOS & DESISTENTES \\
\hline 2011 & 257 & $167(65 \%)$ & $82(31,9 \%)$ & $08(3,1 \%)$ \\
\hline 2012 & 380 & $237(62,4 \%)$ & $122(32,1 \%)$ & $21(5,5 \%)$ \\
\hline 2013 & 169 & $84(49,7 \%)$ & $79(46,7 \%)$ & $06(3,6 \%)$ \\
\hline 2014 & 172 & $98(67 \%)$ & $73(27 \%)$ & $01(0,6 \%)$ \\
\hline 2015 & 279 & $144(51,6 \%)$ & $125(44,8 \%)$ & $10(3,6 \%)$ \\
\hline
\end{tabular}

Fonte: secretaria da EMEF Ver. Abelardo Leão, 2019

O quadro acima mostra os resultados das avaliações de língua portuguesa dos anos de 2011 a 2015. De acordo com a fala dos entrevistados, e os resultados acima, apontam que a forma de avaliação não era processual conforme orientação do PNAIC porque se consideravasomente a prova escrita, considerada por Hoffman 2005 como avaliação porjulgamento.

Outro ponto importante foi que o entrevistado Pedro(2019), desconsiderou a contribuição do programa para melhorar o resultado das avaliações, porque não levaram em consideração outros aspectos importantes dentro das metodologias do 
PNAIC como, por exemplo, a seqüência didática, o trabalho com o lúdico, a quebra da rotina em sala de aula, entre outros.

Todavia, ao analisarmos o quadro dos resultados, percebemos que 0 resultado na avaliação não foi exitoso, o quadro aponta que, do total de 172 alunos matriculados foram aprovados 98 somando um total de (67\%), foram reprovados 73 somando um total de (27\%) e apenas 01 (um) aluno aparece como desistente, somando um percentual de $06 \%$ de alunos evadidos. Esse dado nos chamou atenção, no ano de 2014 que o PNAIC se fez presente na escola, houve uma redução considerável na evasão escolar.

Ao analisarmos o quadro acima percebemos que o PNAIC deixou sua contribuição no sentido de reduzir ou quase zerar a evasão escolar. Dessa forma, existe um contra ponto entre a proposta do programa, com a resposta dada pelo entrevistado que não achou válida a metodologia do PNAIC, pois para ele, não agregou conhecimento, devido os baixos rendimentos estatísticos nas avaliações, não levando em consideração a avaliação processual, proposta pelo programa e defendida por outros teóricos.

Caldeira afirma que:

A avaliação escolar é um meio e não um fim em si mesmo; está delimitada por uma determinada teoria e por uma determinada prática pedagógica. Ela não ocorre num vazio conceitual, mas está dimensionada por um modelo teórico de sociedade, de homem, de educação e, conseqüentemente, de ensino e de aprendizagem, expresso na teoria e na prática pedagógica. (CALDEIRA 2000, p. 122)

De acordo com Caldeira (2000) a avaliação deve ser entendida dentro de uma perspectiva teórica e conceitual, levando em consideração todas as possibilidades de aprendizagem, trabalhando as múltiplas facetas do processo do aprender, e não de forma meritocrática através de atribuição de notas. Baseado nos estudos realizados, nesta pesquisa, constatou-se que essa é também, uma proposição da política do PNAIC, entretanto, esta foi uma prática que não se materializou no contexto da sala de aula, por esse motivo, o programa não atendeu a contento as expectativas propostas. 


\section{3-CONSIDERAÇÕES FIINAIS}

O referido trabalho nos permitiu discutir acerca de uma temática importante para o ensino. "O PNAIC e sua contribuição nos resultados das avaliações internas de língua portuguesa". As condições essenciais para análise desta pesquisa foi interpretação dos dados coletados no ambiente da pesquisa - EMEF Ver. Abelardo Leão.

Ao longo desta investigação foram apresentados, os aspectos que marcaram o processo de ensino e aprendizagem no cotidiano escolar através do estudo sobre a logística do programa PNAIC e suas práticas metodológicas no que tange a contribuição nas avaliações internas de língua portuguesa, fizemos o comparativo das avaliações no ano em que o PNAIC se fez presente na escola e ainda procuramos entender como ocorria a avaliação e o que era avaliado.

Durante este estudo percebemos que o programa PNAIC teve sua existência de fato no período de apenas 1 (um) ano neste caso 2014. Dessa forma, percebemos que o programa não foi executado de acordo com o que foi pactuado, seriam dois anos de formação continuada para os professores, no entanto o programa funcionou apenas um ano. Observamos que faltou o compromisso dos Entes Federados em cumprir com a logística do programa que era a duração de dois anos interruptos, apoio financeiro e materiais didáticos pedagógicos para professores.

Por outro lado, os docentes não utilizaram as metodologias pedagógicas do programa no contexto da sala de aula, não usaram a avaliação processual conforme era proposto,ao contrário disso, continuaram avaliando os alunos somente por meio da prova escrita, aquela que ocorre pelo processo meritocrático, através de notas. Sendo assim, observamos que o PNAIC não conseguiu a contento atender o objetivo proposto no que tange os resultados nas avaliações internas de língua portuguesa.

Porém é perceptível a presença do programa na redução da evasão escolar, pois, no ano de 2014, constatamos uma considerável redução no número de alunos evadidos. Assim, percebemos que é necessário travar mais discussões e reflexões sobre a prática metodológica e o processo avaliativo, principalmente ter consciência no ato de avaliar.

Outro ponto relevante é que precisamos sim criar políticas públicas de formação continuada, porém faz-se necessário que haja o compromisso em executar, 
tanto por parte dos governos quanto da escola, professores e a comunidade de um modo geral, com a finalidade de construir uma prática educativa dinâmica e flexível, que atenda aos anseios dos estudantes e da sociedade.

Ressaltamos ainda que a finalidade da nossa pesquisa seja provocar inquietação em outros pesquisadores a buscar caminhos para uma educação mais inclusiva dentro do local de trabalho, principalmente questionamentos sobre o processo avaliativo como um tema inesgotável de investigação.

Em síntese, entendemos que as políticas públicas de formação continuada e as metodologias avaliativas utilizadas no contexto da sala de aula sejam executadas através do processo inclusivo, com intuito de construir conhecimento e garantir o aprendizado como um direito do aluno, através da democratização e ressignificação do ensino aprendizagem.

\section{REFERÊNCIAS}

BRASIL, Ministério da Educação. Diário Oficial e União. Brasília, 05 de julho 2012a. , Portaria o 867, de 04 de julho de 2012. Institui o Pacto Nacional pela Alfabetização na Idade certa e as ações do pacto e define suas diretrizes gerais. Diário Oficial da União. Brasília, 05 de Julho de 2012c

CALDEIRA, Anna M. Salgueiro. Ressignificando a avaliação escolar. In: Comissão Permanente da Avaliação Institucional:UFMG-PAIUB. Belo Horizonte: PROGRAD/UFMG, 2000. P 122-129 (Cadernos de Avaliação, 3)

FURTADO, D. S. A Formação Docente no PNAIC; concepções as orientações prescritas e ações efetivas no Município de Cametá- Pá, 2015.

HOFFMANN, Jussara M.Avaliação mediadora:Uma prática em construção da préescola à universidade. Porto Alegre: Mediação, 1993a

Lerch. Avaliação: mito e desafio: uma perspectiva consrutivista. - Porto Alegre:Mediação, 2005, 35. Ed. Revista. 1ำ.p. 
LUCKESI,C. 2011. "Avaliação de aprendizagem escolar: estudos e proposições." São Paulo Cortez.

. Avaliação da aprendizagem escolar: estudos e proposições. $15^{\mathrm{a}}$ ed. São Paulo: Cortez, 2003.

NÓVOA, A. Formação de professore profissão docente. In: NÓVOA, A. (orgs). Os professores e sua formação. 2. Ed. Lisboa: Dom Quixote, 1997.

Profissão professor, Antonio Nóvoa, 192 págs, Porto Editora (Porto, Portugal, tel. (- 35122 68-8383,41,36 real. Disponível: https/novaescola.org.

SARTORI, Danieli Ghedin. Construção de sentidos da sobrecarga no trabalho por professores do magistério superior: o tema da saúde via atividade linguageira. 2017. 228 f. Dissertação (Mestrado em Letras) - Universidade Tecnológica Federal do Paraná, Pato Branco, 2013

VASCONCELLOS, Celso. Avaliação: concepções dialéticas libertadora do processo de avaliação escolar. 15 Ed. São Paulo: Libertad, 2005. 